\title{
HEALTH AND PSYCHOSOCIAL StATUS OF PATIENTS WITH TURNER SYNDROME AFTER TRANSITION TO ADULTHOOD: THE BELGIAN EXPERIENCE
}

\begin{abstract}
F. Verlinde ${ }^{a}$, G. Massa ${ }^{a}$, K. Lagrou a, C. Froidecoeur ${ }^{a}$, J.P. Bourguignon ${ }^{b}$, M. Craen ${ }^{c}$, J. De Schepper ${ }^{d}$, M. Du Caju , C. Heinrichs, I. Frangois ${ }^{g}$, M. Maes ${ }^{\mathrm{h}}$ on behalf of the Belgian Study Group of Paediatric Endocrinology ${ }^{a}$ Belgian Study Group of Paediatric Endocrinology (BSGPE), Department of Paediatric Endocrinology, Universities of ${ }^{b}$ Liege, ${ }^{c} G$ Gent, ${ }^{d}$ Brussels, ${ }^{e}$ Antwerp, ${ }^{f}$ Bruxelles, ${ }^{g}$ Leuven and ${ }^{h}$ Louvain, Belgium.
\end{abstract}

KEYWORDS: Turner syndrome, health and psychosocial status - Turner syndrome, transition to adulthood - Turner syndrome, questionnaire.

\section{Abstract}

Background: Most girls with Turner syndrome (TS) are intensively followed by paediatricians, but are lost to follow-up when they reach adulthood. To gain insight into the adult medical and psychosocial situation, we performed a survey in young adult TS patients.

Patients and Methods: A questionnaire concerning current health status, education, occupation and living situation was sent to 160 young adult TS women, all treated during childhood with GH and oestrogen if needed.

Results: We received 102 completed questionnaires. Mean \pm SD age at reception of the questionnaire was $23.4 \pm 3.3$ years, height $153.3 \pm 5.2 \mathrm{~cm}$, body mass index $23.7 \pm 4.9 \mathrm{~kg} / \mathrm{m}^{2}$. Age and auxological parameters were comparable between responders and non-responders. Thirteen $(12.7 \%)$ responders were not under regular medical care; $15(14.7 \%)$ were seen by a general practitioner, while $28(27.4 \%)$ needed several specialists. Forty-one (40.2\%) patients reported health problems. The most frequently reported problem was hypertension (10.7\%), followed by hypothyroidism (5.8\%) and back problems (4.9\%). Twenty-four (23.5\%) of the 41 patients were taking medication for the indicated health problems. Twenty-six (25.5\%) women had undergone spontaneous puberty; 16 of them reported spontaneous menstruations while 10 received oestrogen replacement therapy. Of the 76 women with induced puberty, 11 (14.5\%) were not taking any oestrogen anymore. Compared with the general population, more TS women attended university and more obtained higher education. Forty-six women (45.1\%) were working full-time, 7 $(6.9 \%)$ were unemployed, and $4(3.9 \%)$ received an allocation. Seventy $(68.6 \%)$ patients were still living with their parents, while $18(17.6 \%)$ were living together or married, and $14(13.7 \%)$ were living alone.

Conclusions: The transition of adolescents with TS to adult medical care is not optimal in Belgium. Although $40.2 \%$ of these young women reported health problems, $12.7 \%$ did not consult any physician. Many TS women did not take oestrogen replacement therapy. A specialized multidisciplinary approach for adults with TS is needed in order to optimize health and psychosocial status in these women. 


\section{Introduction}

Turner syndrome (TS) is a genetic disorder caused by the absence of or a structural abnormality of one X-chromosome, affecting approximately $1 / 2,000$ females [1]. The phenotype is characterized by short stature, lack of pubertal development and infertility, and various dysmorphic features. Most of the patients are diagnosed during childhood [2] and received intensive medical follow-up by paediatric endocrinologists taking care of growth-promoting treatment with recombinant growth hormone $(\mathrm{GH})$ and puberty induction with estrogens, if indicated [3]. Although it has been increasingly evident that adults with TS are susceptible to a large range of medical and psychosocial problems [2, 4], little is known about what happens to these patients after transition to adulthood, and many patients seem to "opt out" of the medical milieu when they reach adulthood [5]. Moreover, limited information is available on the long-lasting effect of GH treatment during childhood on health and psychosocial functioning of adult TS women.

In order to gain insight into the actual medical care, health status, educational and occupational status, and psychosocial functioning of young adult TS women treated in Belgium, we sent a questionnaire to 160 young adult TS patients treated during childhood and adolescence with GH and oestrogens if needed to induce puberty. We report the results on the medical and psychosocial status of 102 women with TS who returned a filled out questionnaire.

\section{Patients and Methods}

\section{PATIENTS}

In Belgium, most girls diagnosed with TS are followed by paediatric endocrinologists belonging to the Belgian Study Group for Paediatric Endocrinology (BSGPE). Patient data are stored in the BSGPE database. After completion of growth-promoting treatment and puberty induction, if needed, the patients are referred to an adult specialist, depending on the patients' preferences, the contacts of the paediatric endocrinologist and the availability of a colleague familiar with TS patients. From the database of the BSGPE, containing the auxological data of nearly all GH-treated patients in Belgium since 1987, we retrieved all TS patients who had completed GH treatment for more than 1 year $(n=175)$. The auxological data have recently been published [3]. Patients were born between 1971 and 1985. Fifteen patients were excluded because permission from the ethical committee could not be obtained for one centre (5), because the treating physician was not working with the study group anymore (8), because of autosomal recessive gonadal dysgenesis with normal karyotype (1) or because the patient had deceased (1). 


\section{METHODS}

A questionnaire concerning current medical care, health status, education, occupation and living situation was mailed by the paediatric endocrinologist who had treated the patient during childhood, to the selected subjects. The study was approved by the local ethical committees of the participating centres. In total, 160 questionnaires were sent in autumn 2001. Data collection was closed in February 2002. Seven questionnaires came back undelivered (unknown address). After 36 months, a reminder letter was sent to those patients who did not answer the first time. 102 filled out questionnaires were returned (response rate of 102/153 or 66\%). The responders and nonresponders were compared for karyotype (including ring chromosome), adult height and weight at last paediatric visit, target height, age at start of GH treatment, years of GH treatment, years after stopping GH treatment, occurrence of spontaneous puberty and age at start of oestrogen treatment, if indicated. Concerning current medical care and health status, the patients were asked if they were regularly consulting a physician, if they had any current health problems and if they were taking any medication for these health problems. In addition, we asked the patient for her actual height and weight. Regarding education and occupation we asked whether the patient was actually studying, the type and level of study. The highest diploma obtained was determined. If special education had been followed, the type of this education was specified. For the responders who were not studying anymore, we asked whether they had a job, were searching for a job, stayed at home (housewife) or whether they received an allocation. In addition, we asked whether, according to the responder, the job they practised was lower than, equal to or higher than the education they received. Concerning the living situation, the patients were asked whether they were still living with their parents, with a partner or alone. In addition, we asked if they were single, married, or divorced. These data were compared to the general female Belgian population $[6,7]$.

\section{STATISTICS}

Results expressed as mean \pm SD (range), absolute numbers or percentages. Responders and nonresponders were compared by non-paired $t$ test. Comparisons between the studied TS women and the general female Belgian population were done by $X^{2}$ test. A $p$ value $<0.05$ was considered as significant.

\section{Results}

\section{PATIENT CHARACTERISTICS}

A total of 102 filled out questionnaires were returned. Considering a prevalence of TS of $1 / 2,000$ newborn girls [1], this represents about $25 \%$ of the TS women born in the considered time interval (1971-1985). Table 1 shows the characteristics of the patients who responded to the questionnaire, compared to the non-responders. There were no differences between the groups for the evaluated 
parameters. The age of the patients at the receipt of the questionnaire was $23.4 \pm 3.3$ years (16.930.9 years). The reported height was $153.3 \pm 5.2 \mathrm{~cm}(140-168 \mathrm{~cm})$, which was comparable to the measured height $(152.5 \pm 5.6 \mathrm{~cm})$ at the last visit in the paediatric clinic. The reported weight was $55.9 \pm 11.6 \mathrm{~kg}$, also comparable with the last measured weight $(54.2 \mathrm{~B} \pm 9.0 \mathrm{~kg}$ ). Eleven patients $(10.7 \%)$ were obese, defined as a body mass index $130 \mathrm{~kg} / \mathrm{m}^{2}$. Puberty was induced with ethinyl oestradiol in 76 patients (karyotypes: 45,X: $n=40 ; 45, X / 46, X i(X q): n=14 ; 46, X i(X q): n=5 ; 45, X / 46, X Y$ : $n=4 ; 45, X / 46, X(r X): n=3$; others: $n=3$ ), whereas 26 patients (karyotypes: 45,X: $n=11 ; 45, X / 46, X X: n$ $=4 ; 45, X / 46, X Y: n=3 ; 45, X / 46, X i(X q): n=3 ; 46, X i(X q): n=2 ; 46, X \operatorname{del} X p: n=2 ; 45, X / 47, X Y Y: n=1)$ reported to have developed puberty spontaneously.

Table 1. Characteristics of the responders and non-responders.

\begin{tabular}{lcc}
\hline & Responders & Non-responders \\
\hline Number of patients & 102 & 58 \\
Karyotype $(45, \mathrm{X} / \mathrm{r}(\mathrm{X}) /$ other $)$ & $51 / 3 / 48$ & $30 / 3 / 25$ \\
Age at receipt, years & $23.4 \pm 3.3$ & $23.4 \pm 3.4$ \\
Time since stop GH, years & $6.4 \pm 2.8$ & $6.6 \pm 2.7$ \\
Age at last visit, years & $18.2 \pm 1.6$ & $18.2 \pm 2.3$ \\
Measured height, cm & $152.5 \pm 5.6$ & $150.1 \pm 7.1$ \\
Measured weight, $\mathrm{kg}$ & $54.1 \pm 9.0$ & $53.9 \pm 10.1$ \\
Body mass index, $\mathrm{kg} / \mathrm{m}^{2}$ & $23.7 \pm 4.9$ & $23.8 \pm 3.9$ \\
Target height, cm & $161.4 \pm 5.7$ & $161.8 \pm 5.7$ \\
Age at start GH, years & $11.6 \pm 2.9$ & $11.9 \pm 3.2$ \\
GH duration, years & $5.3 \pm 2.4$ & $4.9 \pm 2.4$ \\
Age at start of ethinyl & & \\
$\quad$ oestradiol, years & $14.5 \pm 1.9$ & $14.7 \pm 2.0$ \\
Induced/spontaneous puberty & $76 / 26$ & $51 / 7$ \\
\hline
\end{tabular}

\section{CURRENT MEDICAL CARE AND HEALTH STATUS}

Table 2 shows the various consulted physicians after transition to adulthood. Thirteen (12.7\%) out of 102 patients did not have any follow-up by a physician. Sixty-two $(60.7 \%)$ women visited only one physician: $15(14.7 \%)$ the general practitioner, $18(17.6 \%)$ the gynaecologist, $20(19.6 \%)$ the adult endocrinologist and $8(7.8 \%)$ the paediatric endocrinologist. Twenty-seven (26.4\%) patients visited several specialists, including the gynaecologist, the paediatric endocrinologist or the adult endocrinologist. Eight patients (7.8\%) visited the general practitioner and another specialist. Other consulted specialists were the cardiologist (2), ENT specialist (2), orthopaedic surgeon (2), dermatologist (2), urologist (1), pneumologist (1), neurologist (1) and psychiatrist (1). Forty-one $(40.2 \%)$ of the responders reported one or more health problems, including hypertension (11 patients), hypothyroidism (6), back problems (5), heart disease (3), migraine (3), asthma (2), knee problems (2), depression (2), epilepsy (2), scoliosis (2), overweight (2), diabetes mellitus (1), hearing problems (1), cholesteatoma (1). Interestingly, only 2 patients reported overweight as a health problem although 11 out of 102 subjects (10.7\%) had a body mass index $130 \mathrm{~kg} / \mathrm{m}^{2}$. Three of the women reporting health problems did not visit a physician regularly, while 17 reported to visit several specialists. In contrast, 5 patients without reported health problems consulted several 
physicians. Medication for these health problems was required in 24 patients (23.5\%). Concerning oestrogen replacement therapy, 65 (85.5\%) of the patients who had an induced puberty were still on oestrogen treatment, while $11(14.5 \%)$ did not take any oestrogen anymore. Of the 26 patients with spontaneous puberty, 10 (38.5\%) were taking oestrogen. All the women with spontaneous puberty without oestrogen treatment reported regular menstruations. From the women with health problems, 8 were not on oestrogen treatment, although they visited a physician regularly and 1 reported back problems.

Table 2. Consulted physicians after transition of women with TS to adulthood.

\begin{tabular}{|c|c|c|c|c|c|}
\hline \multirow[t]{2}{*}{ No follow-up } & \multicolumn{2}{|l|}{ One physician care } & \multicolumn{3}{|l|}{ Combined care } \\
\hline & General practitioner & $15(14.7 \%)$ & General practitioner & $\begin{array}{l}\text { + Gynaecologist } \\
\text { + Adult } \\
\text { endocrinologist }\end{array}$ & $\begin{array}{l}9(8.7 \%) \\
3(3 \%) \\
8(7.7 \%) \\
\end{array}$ \\
\hline & Gynaecologist & $18(17.6 \%)$ & Gynaecologist & + Other specialist & $3(3 \%)$ \\
\hline & $\begin{array}{l}\text { Adult endocrinologist } \\
\text { Paediatric } \\
\text { endocrinologist } \\
\text { Other specialist }\end{array}$ & $\begin{array}{c}20(19.6 \%) \\
8(7.8 \%) \\
1(1 \%)\end{array}$ & Adult endocrinologist & $\begin{array}{l}\text { + Gynaecologist } \\
\text { + Paediatric } \\
\text { endocrinologist } \\
\text { + Other specialist }\end{array}$ & $\begin{array}{l}1(1 \%) \\
2(2 \%) \\
1(1 \%)\end{array}$ \\
\hline $\mathrm{n}=13(12.9 \%)$ & & $\mathrm{n}=62(60.7 \%)$ & & & $\mathrm{n}=27(26.4 \%)$ \\
\hline
\end{tabular}

\section{EDUCATION AND OCCUPATION}

Figure 1 illustrates the education level of the TS women compared to that of the general female Belgian population. Forty-five women (44.1\%) were still studying. Seven (6.8\%) followed special education. Of the 95 women who did not follow special education, 1 patient received no education beyond primary school. Nine $(9.5 \%)$ had only lower secondary education. The majority of the women $(55 / 95 ; 57.9 \%)$ obtained the diploma of higher secondary education; 18 (18.9\%) went on to higher education and 12 (12.7\%) had attended university. Compared to the general female Belgian population [7], more TS women in our survey attended university $(12.7 \mathrm{vs.} 7.7 \%$; $p<0.05)$ and more finished higher secondary education (57.9 vs. 41.1\%; $p<0.05$ ). Forty-six women $(45.1 \%)$ were working full-time; 7 (6.8\%) were unemployed and 4 (3.9\%) were receiving state benefit. Fifteen women (14.7\%) were working in health care as nurse (8), social assistant (2), geriatric helper (2), childcare worker (1), chemist's assistant (1) or speech therapist (1). Another group of 13 responders $(12.7 \%)$ were doing manual work (kitchen help, cleaning), 3 of them in a sheltered workplace. A third group of 15 women (14.7\%) was working in administration as clerks (11), lawyer (2), translator (1), or administrator (1). One was working in education as a teacher. Two women did not specify their occupation. Of the working women, 44 indicated the level of their occupation: 35 (79.5\%) found their job equal to their education, 1 (2.2\%) found her job higher than her education, and 8 (18.2\%) were working below their education. 


\section{LIVING SITUATION}

Sixty-nine (67.6\%) of the TS women were still living with their parents. Eighteen (17.6\%) were living with a partner or were married, and $14(13.7 \%)$ were living alone. One patient did not answer the question. Compared with the general Belgian female population in the same age range, significantly fewer TS women were married ( 7.9 vs. $42.6 \%$ respectively, $p<0.0001$ ), and more of them were still living with their parents (68.3 vs. $38.9 \% ; p<0.0001)$.

Fig. 1. Education of the TS patients compared to the Belgian female population.

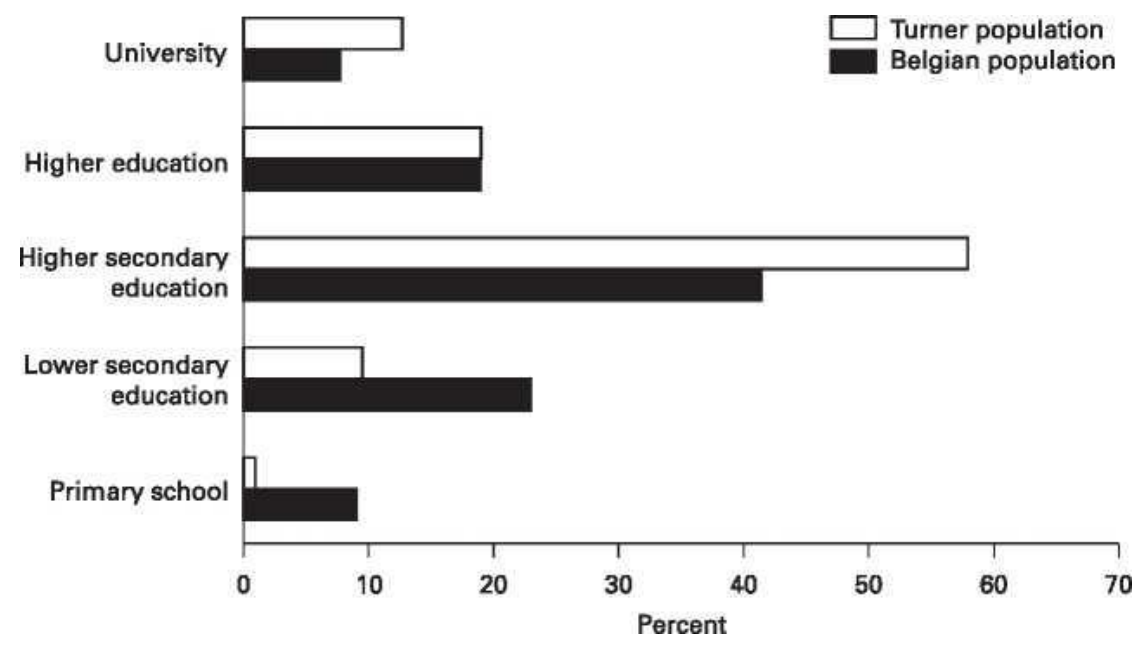

\section{Discussion}

For patients with childhood-onset chronic disorders the transition from paediatric to adultoriented health care is a difficult period for patients and for caretakers [8]. Lack of communication between paediatric and adult care, and the absence of organized caring for adult patients with specific disorders might create clinical and practical problems during the transition period, expanding into adulthood. Paediatric care for TS patients is well centralized and coordinated by the paediatric endocrinologist, taking care of the various aspects of TS [9]. Adult care for patients with TS is less well organized and limited information is available. An American survey in 190 TS women showed that $50 \%$ had visited the endocrinologist, $17 \%$ the cardiologist and $44 \%$ another physician in the previous year [10]. In the UK, Poole and Leatherdale [11] reported that out of 30 adult TS patients, 14 were followed in a general practise, 3 were still followed in a paediatric practise, 9 in a general endocrine clinic, 1 in a general medical clinic and 3 in a dedicated Adult Turner Clinic. Our survey reveals that in Belgium medical care for adult women with TS is inadequate: $12.7 \%$ of the women were not seeing any physician anymore, while $14.7 \%$ only consulted the general practitioner and $26.4 \%$ frequented several specialists. The 10 youngest patients were still taken care of by the paediatric endocrinologist; this may be due to their young age, the immaturity or lack of independence of some TS women [13], but this could also indicate difficulties in transitioning the TS women to adequate adult care. As our data only concern TS 
women who were intensively followed during childhood, we do not have any data on the health status and medical care of TS women who did not receive this follow-up during childhood. Taken together, these data show that the transition to adult health care is suboptimal for most patients with TS. Adolescent TS patients should be informed about all aspects of adult TS life and the need for regular follow-up and preventive health care. In several countries, initiatives to centralize the care for adult TS patients based on local cooperation have been set up, e.g. in the UK, specialized and dedicated Adult Turner Clinics have been established throughout the country [4] and in Sweden a multidisciplinary approach has been developed [12].

Adults with TS are susceptible to a large range of medical disorders and psychosocial problems [3, $4,14]$. Most important are the cardiovascular complications as hypertension, aortic dilatation and dissection, ischaemic heart disease and consequences of congenital cardiac anomalies [14-16]. In our study, $10.7 \%$ of the subjects reported to have hypertension. The most common endocrine complication in TS patients is hypothyroidism [17]. Of our patients, $5.8 \%$ reported to be hypothyroid. Some disorders, like the fertility problems, are important for personal life and might create problems in the life of a couple [2]. Also the high frequency of hearing problems [4, 14] has a major influence on social life. In our study, only 2 patients reported ear problems. Although we studied a relatively young population, this is a rather low number of patients. Maybe the patients do not consider this as a health problem, or they are not aware of the quality of their hearing. Many TS patients are confronted with obesity, increasing in the older population [18]. The discordance between the reported and observed number of patients with obesity in our study population suggests an underestimation of obesity related and maybe also of the other health problems. This may be due to the questionnaire method used, the young age of the patients, or to a tendency to minimize problems and to underestimate the impact as a defence mechanism.

Although there is no doubt about the benefits of oestrogen treatment for adult TS patients, especially if ovarian failure is present, on metabolic aspects [19], uterine development [20], bone mineral density [21, 22] and cardiovascular risk factors [23, 24], many TS women stop their treatment at a relatively young age. In our survey, $14.5 \%$ of the subjects did not continue oestrogen treatment despite ovarian failure. Comparing this result with data from other studies is difficult since these reports are not limited to patients with previous GH treatment and they usually consider a larger age range. In the USA, Cunniff et al. [10] observed that $82 \%$ of the 190 responders were on oestrogen treatment and in Sweden, Landin-Wilhelmsen et al. [12] reported that $85 \%$ of the 283 women with TS were on oestrogen replacement therapy, with a variation of $64-100 \%$ between the different university hospitals. A Danish population study by Gravholt et al. [22] in 322 adult TS patients showed that only $71 \%$ used hormone replacement therapy. In the UK, Conway et al. [18] observed that $22 \%$ of the patients had no oestrogen treatment at their first visit in the Adult Turner Clinic. Poole and Leatherdale [11] studied a small patient group more comparable to ours and reported that all 30 patients in their survey, with previous follow-up in a paediatric endocrine clinic, were on oestrogen treatment. Although our results are better than those from more historical surveys, probably as the result of intensive paediatric follow-up, still an important number of TS patients stop oestrogen treatment early. The indications of long-term sex hormone 
replacement therapy have to be explained to adolescents with TS, and the advantages and disadvantages should be extensively discussed.

In order to improve adult height young girls with TS are nowadays treated with supraphysiological doses of GH [3], which result in high serum IGF-I levels [25]. Our knowledge of the long-term effects of high-dose GH treatment is limited. Some studies reported a relationship between high IGF-I levels and an increased risk for breast cancer [26, 27] and colorectal cancer [28]. In addition, oestrogen replacement therapy might influence the breast cancer risk [29]. Moreover, the longterm metabolic (e.g. insulin resistance) and cardiovascular repercussions of high-dose $\mathrm{GH}$ treatment and oestrogen replacement therapy are poorly defined [23]. This lack of knowledge together with the increasing number of patients treated urges a continued medical surveillance during adulthood. The complexity of the potential problems warrants the establishment of specialized Adult Turner Syndrome Clinics.

The majority of TS patients have a normal intelligence, although verbal intelligence is mostly higher than the performal intelligence. Nevertheless, women with TS can achieve comparable levels of schooling as their family members and the majority enters or completes university or do postgraduate training [30]. Sybert [5] found that 33\% of the adults with TS went to university, compared to $19 \%$ in the normal population and $10 \%$ had a postgraduate degree. Elsheikh et al. [4] reported that $35 \%$ of adult TS patients already obtained or were studying for a university degree in England. Our data confirm that also in Belgium, young TS women are at least as well educated as the general population, but they do not consider themselves to be overqualified for their job.

However, many adults with TS have difficulties with respect to social functioning. Delooz et al. [31] described that the majority of the 20 examined patients had normal intelligence and were socially well adapted, but 50\% expressed feelings of low self-confidence, depression and social insecurity, suggesting that achieving a mature level of psychosocial functioning remains a problem for many TS women. Downey et al. [13] compared 23 TS women with 23 women with constitutional short stature and found that TS women had a lower overall functioning on a global psychological health scale and had more impairment in social functioning. Data on the number of married TS women vary between 4 and $63 \%$, depending on the number and age of the studied patients [5, 13, 32]. In our patients, only $18 \%$ was living with a partner or married. This is partly due to the large number of students in the studied population (44.1\%) but nevertheless significantly more women were living with their parents, compared to the general female Belgian population of the same age.

In summary, our data indicate that in Belgium the transition of adolescents with TS to adult medical care is not optimal. Once the TS woman is discharged from the paediatric clinic, there is still a long way to go, the major goal being to optimize the health and psychosocial wellbeing of these women. The transition period is important in this process. The adolescent patients should be informed about all aspects of adult TS life and the need for regular follow-up and preventive health care. A specialized multidisciplinary approach for the care of adult TS women should be recommended and established if possible. 


\section{Acknowledgements}

This study was supported by the Foundation of the Belgian Study Group for Paediatric Endocrinology. We are grateful to the other members of the Belgian Study Group for Paediatric Endocrinology who took part in this work: D. Beckers, F. de Zegher, M.C. Lebrethon, P. Malvaux, R. Rooman, G. Thiry-Counson, M. Thomas, and M. van Helvoirt. This work was previously published in abstract form [Horm Res 2003 (suppl 2) 157] and was presented as miniposter at the 42nd Annual Meeting of the European Society for Paediatric Endocrinology, Ljubljana, September 2003. 


\section{References}

1 Ranke M, Saenger P: Turner's syndrome. Lancet 2001; 358: 309-314.

2 Ostberg J, Conway G: Adulthood in women with Turner syndrome. Horm Res 2003; 59: 211-221.

3 Massa G, Heinrichs C, Verlinde S, Thomas M, Bourguignon JP, Craen M, Francois I, Du Caju M, Maes M, De Schepper J: Late or delayed induced or spontaneous puberty in girls with Turner syndrome treated with growth hormone does not affect final height. J Clin Endocrinol Metab 2003; 88: 4168-4174.

4 Elsheikh M, Dunger D, Conway G, Wass A: Turner's syndrome in adulthood. Endocr Rev 2002; 23: 120140.

5 Sybert V: The adult patient with Turner syndrome; in Albertsson-Wikland K, Ranke M (eds): Turner Syndrome in a Life Span Perspective: Research and Clinical Aspects. Amsterdam, Elsevier, 1995, pp 205-218.

6 Nationaal instituut voor statistiek 2001: Bevolking en huishoudens. Totale Belgische bevolking op 1.1.2001, pp 112-113.

7 Nationaal instituut voor statistiek 2000: Enquete naar de arbeidskrachten. Totale Belgische bevolking, pp 26-27.

8 Callahan T, Winitzer F, Keenan P: Transition from pediatric to adult-oriented health care: A challenge for patients with chronic disease. Curr Opin Pediatr 2001; 13: 310-316.

9 Frias J, Davenport M: Health supervision for children with Turner syndrome. Pediatrics 2003; 111: 692-699.

10 Cunniff C, Hassed S, Hendon A, Rickert V: Health care utilisation and perceptions of health among adolescents and adults with Turner syndrome. Clin Genet 1995; 48: 17-22.

11 Poole R, Leatherdale B: An audit of adult women with Turner's syndrome: Is surveillance for comorbidity adequate? Clin Endocrinol 2002; 56: 561-562.

12 Landin-Wilhelmsen K, Sylven L, Berntorp K, Karlsson A, Innala E, Ekman B, Bryman I, Wilhelmsen L: Swedish cardiac morbidity study in Turner syndrome; in Saenger P, Pasquino AM (eds): Optimizing Health Care for Turner Patients in the 21st Century. Amsterdam, Elsevier, 2000, pp 137-144.

13 Downey J, Ehrhardt A, Gruen R, Bell J, Morishima A: Psychopathology and social functioning in women with Turner syndrome. J Nerv Ment Dis 1989; 177: 191-201.

14 Gravholt C: Medical problems of adult Turner's syndrome. Horm Res 2001; 56 (suppl 1): 44-50.

15 Sybert V: Cardiovascular malformations and complications in Turner syndrome. Pediatrics 1998; 101: E11.

16 Elsheikh M, Casadei B, Conway G, Wass J: Hypertension is a major risk factor for aortic root dilatation in women with Turner's syndrome. Clin Endocrinol 2001; 54: 69-73.

17 Sylven L, Hagenfeldt K, Brondum-Nielsen K, von Schoultz B: Middle-aged women with Turner syndrome: Medical status, hormonal treatment and social life. Acta Endocrinol 1991; 125: 359-365. 
18 Conway G, Elsheikh M, Cadge B, Ostberg J: Adult Turner follow-up - The Middlesex experience; in Saenger P, Pasquino AM (eds): Optimizing Health Care for Turner Patients in the 21st Century. Amsterdam, Elsevier, 2000, pp 295-306.

19 Gravholt C, Klausen I, Weeke J, Christiansen J: Lp(a) and lipids in adult Turner's syndrome: Impact of treatment with $17 \beta$-estradiol and norethisterone. Atherosclerosis 2000; 150: 201-208.

20 Snajderova M, Mardesic T, Lebl J, Gerzova H, Teslik L, Zapletalova J: The uterine length in women with Turner syndrome reflects the post-menarcheal daily estrogen dose. Horm Res 2003; 60: 198-204.

21 Landin-Wilhelmsen K, Bryman I, Windh M, Wilhelmsen L: Osteoporosis and fractures in Turner syndrome - Importance of growth-promoting and estrogen therapy. Clin Endocrinol 1999; 51: 497-502.

22 Gravholt C, Vestergaard P, Hermann A, Mose- kilde L, Brixen K, Christiansen J: Increased fracture rates in Turner's syndrome: A nation-wide questionnaire survey. Clin Endocrinol 2003; 59: 89-96.

23 Gravholt C, Naeraa R, Nyholm B, Gerdes L, Christiansen E, Schmitz O, Christiansen J: Glucose metabolism, lipid metabolism and cardiovascular risk factors in adult Turner's syndrome: Impact of sex hormone replacement. Diabetes Care 1998; 21: 1062-1070.

24 Elsheikh M, Bird R, Casadei B, Conway G, Wass A: The effect of hormone replacement therapy on cardiovascular hemodynamics in women with Turner's syndrome. J Clin Endocrinol Metab 2000; 85: 614-618.

25 Massa G, Bouillon R, Vanderschueren-Lodeweyckx M: Serum growth hormone (GH)-binding protein and insulin-like growth factor-I levels in Turner's syndrome before and during treatment with recombinant human GH and ethinyl estradiol. J Clin Endocrinol Metab 1992; 75: 1298-1302.

26 Hankinson S, Willett W, Colditz G, Hunter D, Michaud D, Deroo B, Rosner B, Speizer F, Pollak M: Circulating concentrations of insulinlike growth factor-I and risk of breast cancer. Lancet 1998; 351: 13931396.

27 Toniolo P, Bruning P, Akhmedkhanov A, Bonfrer J, Koenig K, Lukanova A, Shore R, ZeleniuchJacquotte A: Serum insulin-like growth factor-I and breast cancer. Int J Cancer 2000; 88: 828-832.

28 Giovannucci E, Pollak N, Platz E, Willett W, Stampfer M, Majeed N, Colditz A, Speizer F, Hankinson S: A prospective study of plasma insulin-like growth factor-1 and binding protein-3 and risk of colorectal neoplasia in women. Cancer Epidemiol Biomarkers Prev 2000; 9: 345-349.

29 Beral V, Million Women Study Collaborators: Breast cancer and hormone-replacement therapy in the Million Women Study. Lancet 2003; 362: 419-427.

30 Rovet J: The psychoeducational characteristics of children with Turner syndrome. J Learn Disabil 1993; 26: 333-341.

31 Delooz J, Van den Berghe H, Swillen A, Kleczkowska A, Frijns JP: Turner syndrome patients as adults: A study of their cognitive profile, psychosocial functioning and psychopathological findings. Genet Couns 1993; 3: 169-179.

32 Pavlidis K, McCauley E, Sybert VP: Psychosocial and sexual functioning in women with Turner syndrome. Clin Genet 1995; 47: 85-89. 